\title{
El legado de los emperadores hispanos
}

FICHA BIBLIOGRÁFICA

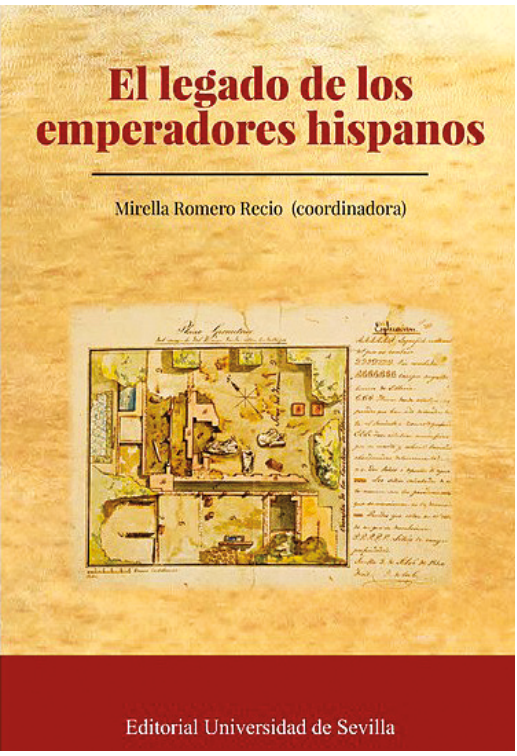

Mirella Romero Recio (Coordinadora), El legado de los emperadores hispanos. Sevilla, Editorial Universidad de Sevilla, Colección Historia y Geografía no 348, 2018, 221 págs. + figs. ISBN: 978-84-472-2838-6.

\section{Gloria Mora I Universidad Autónoma de Madrid}

LA CONMEMORACIÓN DEL 1900 ANIVERSARIO DE LA MUERTE DE TRAJANO en 117 d.C. y el ascenso de Adriano al poder generaron en 2017 y 2018 varias reuniones científicas y exposiciones ${ }^{1}$ que han proporcionado una nueva visión de estos dos emperadores, revisando la historiografía antigua y moderna y confrontándola con la arqueología más reciente.

Precisamente el libro que comentamos surge de un workshop celebrado en la Universidad Carlos III de Madrid el 21 de abril de 2017 con el mismo título y prácticamente los mismos participantes. Es uno de los resultados del proyecto coordinado I+D financiado por

1. Traiano. Costruire l'Impero, creare l'Europa en el Museo dei Fori Imperiale (Mercati di Traiano), y Adriano-Metamorfosis. El nacimiento de una nueva Roma, en el Museo Arqueológico de Sevilla. 
el Ministerio de Economía y Competitividad, integrado por "La construcción de la imagen de los primeros emperadores hispanos (siglos XV-XX). Un análisis historiográfico de la interpretación de la diversidad", dirigido por la profesora Mirella Romero Recio (UC3M), y por "Adriano y la integración de la diversidad regional. Una perspectiva histórica e historiográfica”, codirigido por el profesor José Manuel Cortés Copete y la profesora Elena Muñiz (Universidad Pablo de Olavide de Sevilla).

El libro, coordinado por la profesora Mirella Romero Recio, está dedicado a la recepción e interpretaciones de Trajano y Adriano en época moderna, en el marco del uso generalizado de la Antigüedad con diversos fines ideológicos. Consta de once textos de nueve investigadores españoles (de las Universidades Carlos III de Madrid, Complutense, Sevilla y Pablo de Olavide) y de una italiana (Istituto Centrale per l'archeologia) sobre la construcción de la imagen o imágenes de Trajano y Adriano en la historiografía desde distintas perspectivas, con una cronología que va desde la misma época de Trajano hasta comienzos del siglo $\mathrm{XX}$, si bien hay continuas y muy útiles menciones a la investigación actual, sobre todo en arqueología. Todos los textos, salvo dos, se centran en la historiografía hispana, y se suceden - y a veces se solapan - en orden cronológico: tres sobre Trajano, cuatro sobre Adriano, y tres más sobre Trajano y Adriano en la arqueología de Itálica, en obras de arqueología españolas de los siglos XIX y primer tercio del XX, y en el pensamiento nacionalista andaluz.

Ya en su texto introductorio Mirella Romero Recio señala la diferente consideración y valoración que la historiografía antigua y moderna ha prestado a Trajano (elogios) y a Adriano (críticas). Trajano, considerado por sus contemporáneos como uno de los mejores emperadores, fue rápidamente cristianizado y mostrado como exemplum virtutis durante la Edad Media y Moderna, especialmente en España por el hecho de haber nacido en Itálica; por el contrario, la historiografía, a partir de la Historia Augusta, ha solido fijarse en los defectos de Adriano o bien, en el caso de la historiografía hispana, procurado no mencionarlos. No obstante, ambos tendrán un papel protagonista en la historiografía española por el hecho de ser de origen hispano.

Jaime Alvar, director del Instituto de Historiografía Julio Caro Baroja, inaugura el libro con un texto sobre "La cristianización de Trajano", cuestión fundamental para entender su protagonismo en la historiografía posterior. El proceso de sublimación comienza coetáneamente con el Panegírico en el que Plinio el Joven atribuye a Trajano todas las virtudes del buen gobernante, mereciendo por ello el título de Optimus Princeps otorgado por el Senado en 114 d.C. (¿o 103, según las monedas?), y convirtiéndose así en modelo de gobernantes frente a la imagen negativa de Calígula o Domiciano proporcionada por las fuentes. Cómo se gesta esta imagen, que se asentará y perdurará en la historiografía, a partir del Panegírico como documento de propaganda política favorecida por la oligarquía y seguida por Dión de Prusa, Amiano Marcelino, Eutropio o Aurelio Víctor, "artífices ... de la fama de Trajano", fundamentada en la combinación de las cualidades de un gobierno absoluto con el respeto a las instituciones republicanas, además de extender al máximo los límites del Imperio (p. 16). Imagen que consolida la historiografía cristiana, tema central del texto de Alvar: el proceso de cristianización del emperador al que incluso se le atribuye la tolerancia hacia los cristianos (Eusebio de Cesarea), como demuestra la extendida leyenda medieval acerca de su clemencia y justicia con la viuda, que redundará en la salvación de su alma por intercesión de Grego- 
rio Magno, obispo de Roma entre 590 y 604. Una leyenda que se inserta "en el contexto del debate sobre las propiedades de la oración y la posibilidad de la salvación retrospectiva” (p. 21), y que conocemos por varias fuentes prácticamente coetáneas: en Oriente, el relato de Juan Damasceno, a principios del s. VIII; en Occidente, en la misma época, el de un monje de la abadía benedictina de Whitby, al norte de Inglaterra, y el de Juan el Diácono en su Vita Gregorii, en la segunda mitad del siglo, sintetizados en la Legenda Aurea a mediados del s. XIII. Alvar señala, sin embargo, que la anécdota habría pertenecido en realidad a Adriano, según Dión Casio, pero acabó atribuyéndose a Trajano debido a la creciente fama de éste como buen gobernante por sus virtudes hasta el punto de ser digno de ganar la salvación de su alma pese a no estar bautizado.

María Jesús Fuente, en "Un emperador en el taller: construcción y reconstrucción de la figura de Trajano a lo largo de la Edad Media", avanza y profundiza en el tema tratado por Alvar: las transformaciones experimentadas por la imagen de Trajano como príncipe cristiano desde la Antigüedad Tardía (véase los elogios de Claudiano a fines del s. IV) y durante la Edad Media, a partir del episodio de "la justicia de Trajano", o representación en la literatura y el arte de la leyenda de la viuda que pide justicia al emperador y la salvación del alma de Trajano por intercesión del papa Gregorio Magno. Un episodio que aparece especialmente en tres momentos, siempre vinculado a un interés por presentar a Trajano como máximo ejemplo de buen gobernante por sus virtudes políticas, militares y morales, y, por tanto, como modelo para reyes y emperadores contemporáneos: a mediados del s. IX en versión de Juan el Diácono, a mediados del XII con Juan de Salisbury y su Policraticus, y en el XV con Cristina de Pizán (y difundido también por Dante en varios pasajes de su Divina Comedia). Es interesante el planteamiento de la autora: muestra cómo Trajano va perdiendo sus rasgos anticristianos (pese a la actitud muy crítica del cardenal Baronio) a medida que se consolidan sus cualidades y virtudes (justicia, clemencia, generosidad...), propias del buen gobernante; al mismo tiempo vincula estos cambios a conflictos políticos y religiosos de las distintas etapas del proceso. De ahí que se convierta en modelo para la educación de reyes y príncipes (por ello Cristina de Pizán atribuye la misma anécdota de la viuda a Carlos V de Francia). En resumen, a lo largo de la Edad Media se va creando una imagen de Trajano que llega consolidada al Renacimiento.

Esta imagen es recogida por Mirella Romero Recio en el capítulo dedicado a "Trajano. De gobernante ideal a personaje dramático en la España del siglo XVIII". La autora indaga en la influencia del Panegírico de Plinio sobre el tratamiento de ambos emperadores durante la Ilustración española, concretamente en la literatura política y teatral. Parte de la comparación de Trajano y Felipe IV planteada ya por Luis Morales Polo en su Epítome de los hechos $y$ dichos del emperador Trajano (1654), cuya intención es exaltar las virtudes y logros de un emperador romano de origen hispano en el contexto de decadencia del Imperio español (texto que curiosamente vuelve a utilizarse en 1808 contra los franceses). Es el teatro uno de los medios de mayor difusión de la fama de Trajano y sus virtudes, pero incluye también a Adriano. La autora se centra en el drama Trajano en Dacia, y cumplir con amor y honor, de José de Cañizares (1735), que se inspira ampliamente en Adriano en Siria, libreto de Pietro Metastasio estrenado en Viena en 1732, y en el que Cañizares demuestra conocer las fuentes clásicas sobre la vida de ambos emperadores (Dión Casio, Historia Augusta, etc.). Así, Cañi- 
zares redime a Adriano de sus defectos haciéndole rechazar sus aficiones y caprichos y asumir sus obligaciones como gobernante por el bien del Imperio, aunque nunca llegó a poder compararse con Trajano. Esta doble presencia la encontramos también en el arte: en 1774-76 Mengs pintó en el Comedor y Sala de Audiencias de Carlos III en el Palacio Real de Madrid una Apoteosis de Trajano en la que, según José Nicolás de Azara, ambos gobernantes eran equiparables en virtudes, si bien Carlos III superaba al romano por ser un príncipe verdaderamente cristiano. Años después, en 1797, Mariano Salvador Maella decoró la Sala de Vestir de Carlos IV con una Apoteosis de Adriano.

De Trajano en el siglo XVIII pasamos a Adriano con el texto de Elena Calandra: "Atheniensium studia moresque hausit. L’immagine della Grecia nella storiografia su Adriano". Se trata de una extraordinaria síntesis sobre la profunda helenicidad de Adriano según la diferente información aportada por las fuentes latinas, las griegas y las cristianas. Si bien las fuentes se centran en la influencia de la Atenas clásica en Adriano, la documentación arqueológica muestra una imagen muy distinta y plural que reúne la variedad de las influencias recibidas por Adriano (la época helenística, el Egipto faraónico y alejandrino) y amplía sus actividades políticas, culturales y edilicias. Entre estas últimas cabe mencionar la Villa de Tívoli, que Calandra relaciona con la admiración de Adriano por Alejandro, manifestada también en otras actividades como la caza, la fundación de ciudades con su nombre y construcciones en Atenas y en Roma. Las fuentes reflejan, además, la formación de Adriano en todos los ámbitos de la vida griega: no sólo la lengua y las costumbres, sino también la medicina, las ciencias y el arte; el resultado es un estudioso completo que trasciende, como afirma la autora, el tópico del graeculus de matiz despreciativo (en la historiografía moderna) para convertirse en graecus, de Hadrianus a Hadrianós.

En "Adriano y la religión egipcia. Perspectivas pasadas y presentes", Elena Muñiz Grijalvo presenta la relación de Adriano con los cultos egipcios, una relación no comentada por las fuentes pero que constituye un tema importante en la investigación sobre la religiosidad del emperador. El objetivo de este texto es analizar las teorías antiguas y modernas al respecto y las posibles vías de investigación futuras. La escasa y contradictoria información de las fuentes sobre Adriano y la religión llevó a construir una imagen dicotómica mantenida por los estudiosos en los siglos XIX y XX: en el s. XIX, un Adriano que buscaba satisfacción espiritual en los cultos extranjeros, incluyendo la magia y la adivinación; en el XX, un Adriano escéptico que utilizó la religión romana tradicional como instrumento político. Es ésta la tesis que acaba asentándose. Pero como explica la autora, el panorama es mucho más complejo y necesita ser analizado desde otros puntos de vista. En primer lugar es preciso tener en cuenta qué se entiende en la historiografía moderna por religión y sentimiento religioso, ya que ello ha condicionado su postura, contribuyendo de manera errónea y anacrónica a deslindar la práctica religiosa de Adriano de su actividad política. Por otro lado, Muñiz Grijalvo destaca la complejidad de la llamada "religión egipcia", que comprende los cultos faraónicos, los alejandrinos de época helenística y la interpretatio romana, confluyendo en el culto a Antinoo tan denostado por las fuentes.

Juan R. Ballesteros nos traslada a la historiografía renacentista francesa en "El jardín y el monstruo: la Historia Augusta y el emperador Adriano en el Humanismo". Reconoce que la $H A$ es la mejor fuente para conocer la vida de Adriano a pesar de las dificultades que pre- 
senta la información, y cita las palabras de Sir Ronald Syme que la calificó de jardín delicioso a la vez que monstruo. Por ello el objetivo de su texto, complejo y denso pero apasionante, es rastrear la recepción de la HA en Francia durante los siglos XVI y XVII, cómo fue leída por tres eruditos - Vincent de la Loupe (Vincentius Lupanus), Isaac Casaubon y Claude Saumaise - y cómo analizaron dos pasajes concretos: Marc. 19, 1-4, relativo a la emperatriz Faustina, y la carta de Adriano a su cuñado Serviano a propósito de su estancia en Egipto, recogida en Quad. Tyr. 8, en la que aparecen ya los tópicos que perdurarán a lo largo de la Historia, como la imagen viajera de Adriano (si bien la historiografía moderna en general no ha aprovechado la vinculación de los viajes con la acción política, como sí hicieron los humanistas que protagonizan este trabajo). El autor analiza el contexto histórico en el que se desarrollaron tales exégesis (las guerras de religión, la consolidación de la monarquía absoluta en Francia) así como la metodología humanista, concluyendo con una reivindicación de estas lecturas e interpretaciones porque enlazan, como precedente, con el punto de vista "burlesco y satírico" con el que se considera hoy la serie de biografías, así como quizá aportar soluciones o mostrar cómo aprovechar esta obra como fuente histórica. En este sentido disiente de las más recientes aproximaciones a la $H A$ (por Anthony Birley), que fragmentan el texto en lugar de considerarlo de forma global; esta visión de conjunto sería, en opinión de Ballesteros, el procedimiento más adecuado para penetrar en el significado de la obra y en la intención de su autor, que posiblemente fuera ofrecer una sátira de crítica política.

Juan Manuel Cortés Copete, autor de "Adriano en la encrucijada. Historia e historiografía, antiguas y modernas", centra su muy documentado estudio en el uso político del pasado como una práctica impulsada por Adriano para elaborar un nuevo discurso político, basado en la integración cultural y en el respeto a las identidades provinciales, regionales y ciudadanas. El problema es que este discurso aparece desdibujado en las fuentes, a causa fundamentalmente de dos problemas señalados por Cortés Copete: por un lado, la visión negativa del gobierno de Adriano prevalente en la $H A$ (y en cierto modo también en Dion Casio); por otro, la enorme cantidad de información de carácter artístico, literario e historiográfico producida por la promoción de la cultura vinculada a este nuevo discurso imperial, que ha dificultado un estudio global de tales testimonios. Por lo que respecta al uso del pasado, el autor se centra en el caso de Itálica considerada como una "invención adrianea". Así, en la recuperación histórica de la Itálica de Adriano se mezclarían ideas antiguas que aparecen por primera vez en la $H A$, intereses de la historiografía de época moderna y estudios locales. En este sentido el texto enlaza en parte con el siguiente de José Beltrán, aunque ambos mantienen opiniones opuestas en la cuestión de la fundación de Itálica. Para Cortés Copete, la tradición sobre la fundación antigua de Itálica por Escipión en 205 a.C. no se fundamenta en las fuentes republicanas, que no mencionan este episodio, sino en la misma época de Adriano y de su mano, con el fin de "engrandecer la cuna de su familia" y buscar "un perfil que pudiera arraigarlo en diversas regiones del Imperio" (p. 140). A este respecto traza un interesantísimo cuadro de la transmisión de la tradición a partir de la traducción latina de la Iberia de Apiano leída por Rodrigo Caro, que menciona a Escipión como fundador de Itálica, cuna de los emperadores Trajano y Adriano, dato al que el erudito sevillano añadió la noticia conservada en HA, Hadr. 1,1 acerca de los orígenes remotos de la familia de Adriano en la ciudad de Hadria, para establecerse después en la recién fundada Itálica. Ésta es la idea que se consolida y 
perdura en la historiografía hasta la actualidad. En palabras de Cortés Copete, "la fundación escipiónica de Itálica está tan firmemente incorporada a la tradición historiográfica que no sólo aparece en las obras dedicadas a la ciudad o al emperador Adriano, sino también en los tratados sobe la República Romana y las Guerras Púnicas" (pp. 139-140). La consecuencia de este proceso de ensalzamiento de la patria fue la ampliación y monumentalización de la ciudad, ya convertida en Colonia Aelia Augusta Italica, tema sobre el que la arqueología viene aportando información ya desde las primeras excavaciones sistemáticas en el siglo XVIII.

Y es esta nueva fuente, la arqueología, el asunto al que José Beltrán Fortes dedica su texto "La arqueología de Itálica de época de Trajano y Adriano", indagando sobre la importancia de Itálica (identificada ya desde el siglo XVI) en la historiografía y la arqueología españolas, en buena medida sólo por haberse creído tradicionalmente cuna de los emperadores Trajano, Adriano y Teodosio, e incluso de Silio Itálico. Esta arraigada creencia determinó la interpretación posterior de los restos monumentales de la ciudad, por lo que resulta muy oportuna la presentación de una breve historia de la investigación y de las excavaciones, así como de los cambios en la interpretación de los monumentos, ya que ha condicionado la atribución de los vestigios más importantes de Itálica a una cronología trajanea y adrianea. Un ejemplo es el teatro y la zona NE de la ciudad (pp. 170-173), que a la luz de los estudios más recientes (Pilar León, Antonio Caballos, entre otros) debe considerarse no un "barrio adrianeo" sino parte de la "ciudad de Adriano". Se constata, pues, la importancia de la historia de la arqueología para conocer hallazgos, algunos ya desaparecidos, así como los lugares en que aparecieron, o para reconstruir la situación de las ruinas antes de desaparecer víctimas de las obras públicas. Así, destaca el valor de las acuarelas de Demetrio de los Ríos (cuyo dibujo del epígrafe CIL II 1119 también aprecia Cortés Copete, pp. 145 ss.), que dejan constancia de los mosaicos aparecidos en sus excavaciones en las décadas de 1860 y 1870 y hoy perdidos.

Como complemento a los hallazgos e interpretaciones arqueológicas hay que considerar el tema tratado por Jesús Salas Âlvarez en "Los emperadores hispanos en las obras españolas de Arqueología desde mediados del XIX a mediados del XX”. Analiza los avances y pervivencias en la historiografía arqueológica española a lo largo de cinco etapas: la anticuaria de la primera mitad del siglo XIX (con las obras de recopilación y síntesis de Juan Agustín Ceán Bermúdez y Miguel Cortés y López), la arqueología liberal representada en los trabajos pioneros de Basilio Sebastián Castellanos de Losada, la obra científica de Hübner en la segunda mitad del XIX, especialmente La arqueología de España (1888), los materiales españoles enviados a la gran Mostra Archeologica celebrada en Roma en 1911, recogidos por Manuel Gómez-Moreno y José Pijoán en Materiales de Arqueología Española (1912), y, finalmente la aportación de José Ramón Mélida en el primer tercio del siglo XX. En todas estas obras e iniciativas vemos hasta qué punto pervive la tradición, pues reiteradamente se destaca la labor arquitectónica y de embellecimiento de ciudades de Trajano y, en menor medida, de Adriano (a causa del rechazo general, ya comentado, a ciertas facetas de su personalidad): el puente de Alcántara, los monumentos italicenses, la reparación de calzadas, la reconstrucción del teatro de Mérida, etc., que significativamente se ponen en relación con las grandes construcciones coetáneas en otras ciudades del Imperio, como la Columna Trajana en Roma y el puente sobre el Danubio, en el caso de Trajano, o la Villa de Adriano en Tívoli. Entre otros materiales antiguos de España que se llevaron a la Mostra de Roma destacan pre- 
cisamente varias estatuas y bustos de Trajano y Adriano procedentes de Itálica y de Mérida. Y las mismas apreciaciones aparecen en la Arqueología Española (1929) y la Arqueología Clásica (1933) de Mélida, obras concebidas como síntesis actualizadas de la disciplina para uso de estudiantes universitarios y profesionales.

El último texto del libro corresponde a Fernando Lozano Gómez: "Los emperadores hispanos en los orígenes del nacionalismo andaluz: los casos de Joaquín Guichot y Blas Infante". No deja de citar el autor (él mismo editor de Guichot) la amplia bibliografía existente sobre el papel de la Antigüedad en la construcción del nacionalismo andaluz, pero él se centra en la interpretación del legado de los emperadores hispanos en las obras de sus dos principales teóricos: Joaquín Guichot y Parody en la Historia General de Andalucía (18691871), origen de la identidad andaluza, y Blas Infante en Ideal Andaluz (1915) y Fundamentos de Andalucía (1930-1936), verdaderos referentes de dicha identidad. Ambos coinciden en la valoración positiva de Trajano y Adriano, pero con ciertas diferencias significativas que, como bien explica Lozano, tienen que ver con el distinto ambiente político vivido por ambos pensadores y con los avances de la investigación arqueológica en los más de cuarenta o sesenta años que median entre las obras mencionadas (véase la interesante nómina de autores en pp. 214-216). Guichot concibe la historia de Andalucía como la de un pueblo llegado de Oriente tras el Diluvio con una cultura ya consolidada, la turdetana, que se irá mezclando con la de los siguientes pueblos invasores de la Península y de este modo enriqueciéndose y progresando, lo que explica el elogio del papel de la Bética (representada por los emperadores hispanos) en la política romana. Por cierto que esta idea de la superioridad y mayor antigüedad de la civilización turdetana, anterior a Grecia y Roma, seguía vigente a comienzos del siglo XX, por ejemplo en el Tartessos de Schulten (1922), que tanta influencia tuvo en los Fundamentos de Infante y en otros autores. También Infante defendió la tesis del origen remoto de la civilización "andaluza", que mantuvo su espíritu esencial pese a "las frecuentes infusiones de sangre extraña” (Ideal..., p. 33), pero consideraba que las dos épocas más importantes de la historia de Andalucía habían sido aquellas vinculadas a su "libertad", es decir, la tartésica y al-Andalus.

Para terminar, querría señalar que esta obra no es sólo el resultado de un proyecto de Historiografía y recepción de la Antigüedad clásica desarrollado en el Instituto de Historiografía, en este caso bajo la dirección de M. Romero Recio. Los estudios de historiografía son o deben ser siempre complejos e interdisciplinares, y en este libro se cumplen sobradamente los requisitos. En primer lugar, en los distintos trabajos que lo componen se hace una puesta al día de los problemas historiográficos planteados por las fuentes grecolatinas (sobre todo las correspondientes biografías en la Historia Augusta) respecto al legado de Trajano y Adriano, y, especialmente, de los debates y nuevas propuestas en los estudios actuales sobre la personalidad y las actividades de Adriano. Por otro lado, no sólo traza la construcción de la imagen o - mejor - imágenes de los llamados emperadores hispanos, sino que los conecta con la tradición elaborada y reelaborada por las fuentes desde época coetánea, mostrando cómo y hasta qué punto dicha tradición ha influido en la interpretación de ciertos monumentos y vestigios que, por su calidad, fueron en su momento adscritos a Trajano o a Adriano y ven ahora rebatida o discutida su cronología (caso de Itálica). 
En este sentido la obra comentada va mucho más allá de lo que el título expresa, resultando de enorme utilidad, tanto para los estudiosos de Historia Antigua y Arqueología como para los interesados en Historiografía, al presentar una visión de conjunto - pero no por ello menos profunda y rigurosa - de los problemas y discusiones en torno a la complejidad de las fuentes sobre Trajano y Adriano desde la Antigüedad hasta nuestra época, y al mismo tiempo abriendo nuevas líneas de investigación. En definitiva, el libro responde plenamente a los objetivos planteados por Mirella Romero Recio como coordinadora del volumen: estudiar la Antigüedad y sus usos políticos en la Historia posterior a través de la historiografía antigua y moderna y de la arqueología, en este caso teniendo como eje las figuras de los emperadores antes llamados "españoles". 